\title{
Consumer purchase regret: how personality influences outcome regret and process regret
}

\author{
Zulkarnain \\ Ferry Novliadi \\ Siti Zahreni \\ Lila M. Iskandar
}

Faculty of Psychology, Universitas Sumatera Utara, Medan, Indonesia

\begin{abstract}
Keywords
consumer, purchase, outcome regret, process regret, personality, neuroticism
\end{abstract}

\begin{abstract}
Consumers will evaluate the products they have purchased, whether the product meets their need. The discrepancy between what they want and what they have purchased may lead consumers in purchase regret. Personality plays an important role in determining of consumer purchase regret. The aims of this study are to investigate personality influences toward consumer post purchase regret. This study was quantitative and involved 207 undergraduate students at state University in Medan, Indonesia. The statistical analysis showed that Big Five personality traits; extraversion, agreeableness, conscientiousness, neuroticism, and openness to experience were related to post purchase regret, even outcome regret or process regret. The result confirms that anticipated regret is proved to lead to increased levels of effort, when consumer executes his/her behavioural intentions. Behavioural intentions are more likely to motivate and energize the target behaviour when they embodied with anticipated regret. These findings indicate that it is important for managers to focus on the antecedents of regret and to mitigate its consequences.
\end{abstract}

Corresponding author: Zulkarnain

Email addresses for corresponding author: Zulkarnain3@usu.ac.id

First submission received: $27^{\text {th }}$ December 2017

Revised submission received: $25^{\text {th }}$ February 2018

Accepted: 27th March 2018

\section{Introduction}

In competitive world market, it is important to understand consumers feeling after purchase including their satisfaction, regret and negative emotions (Bui, et al 2011). Consumers often make purchase decisions while uninformed about their true valuations for a product or service. Such decisions have emotional consequences once uncertainties are resolved, and consumers learn if they have made, in hindsight, the wrong choice. Consumers face excessive information and difficult to process all product or service information, before making a choice. This condition leads consumers to receive unexpected results relating to a brand they are not aware of and not considered, after a purchase has made (Lin, 2006).

In recent years, students from many different disciplines realized that regret is not only an affective reaction to bad decision outcomes or processes, but also that it is a powerful force in motivating and giving direction to behaviour (Zeelenberg \& Pieters 2007). After purchase a product, consumers will evaluate the products they purchased, whether the product is in accordance with the purpose or the product can meet their needs (Hawkins, et al., 2007). In purchase decisions, consumers often regret the choices they have made. The consequences of regret are costly for companies because they lost costumer.

Regret is omnipresent and only few of us are free from regrets (and this comes at a very high price). Regret is the emotion that we experience when realizing or imagining that our current situation would have been better, if only we had decided differently (Zeelenberg \& Pieters 2007). Regret is a specific emotion that has a profound impact on decision-making. It guides behaviours since people often tend to avoid it (M’Barek \& Gharbi, 2012).

Regret is motivated consumers to avoid, suppress, deny, and regulate should they experience it (Lee \& Cotte, 2009). When they compare a product and found that, the product is less favorable or products that have different, it is referred to as the outcome regret (Zeelenberg \& Pieters, 2007).

www.jbrmr.com A Journal of the Academy of Business and Retail Management (ABRM) 
According to Lee and Cotte (2009), post-purchase outcome regret is a comparison between what has bought and what could have bought. Regret is evoked when consumers compare their inferior decision process to a better alternative decision process. They feel regret if the foregone outcome is, or is perceived to be, better than the current outcome (Lee \& Cotte, 2009). Consumer will choice foregone alternative when they purchase a product.

Lee and Cotte (2009) also explain that instead of comparing the outcomes, consumer regret due to process, when they compare the decision processes. A sense of regret emerges through the process of comparing the value of the product by comparing the product to purchase with the products that have purchased by consumers. Consumers can regret if they feel that they have failed to implement the decision process as they intended (Lee \& Cotte, 2009). Some studies also suggest that the process of regret related to the quality of the decision-making process of the purchases made by consumers (Connolly \& Zeelenberg, 2002).

Zeelenberg and Pieters (2007) state that there are two components in the process of repentance is remorse happens when lack of consideration and regret occurs when too many considerations in buying a product. The first component may occur due to two things, the sense of failure to carry out the decisionmaking process for their inconsistent behaviour (for example; the desire to buy clothes because the quality is good, but there is another dress that caught the attention of the colour but not the quality) and the belief that they still need information to make good decisions (for example, when consumers want to buy clothes, they do not find good information about these clothes).

Thus, the core of this component focuses on how consumers can do many things in order to change the decision to get a better result. The second component is the regret of too many considerations in buying a product. This condition causes consumers less able to maximize purchase based on amount of information. Consumer feels regret when they intended to do was not executed properly (Lee \& Cotte, 2009).

Regarding to regret, Creyer and Ross (1999) suggested that personality characteristics as factors of regret. Personality characteristics can lead to a predisposition in the decision to make a purchase (McElroy \& Dowd, 2007). Big Five Personality consists of five personality traits. These five basics are used to describe differences in cognitive, behavioural, affective, and social. These five basic dimensions often interpreted as a model of the Big Five Personality and tend to be stable over the life span. McCrae, Robert and Costa (2008) identified big five personality as Extraversion, associated with being outgoing, social able, confident and enthusiastic; conscientiousness associated with being responsible, ambitious, industrious and thorough; Openness to experience, associated with being broad-minded, imaginative, original and curious; Agreeableness, associated with being cooperative, good-natured, forgiving and generous; and neuroticism associated with being moody, worrying, insecure and inhibited.

The aim of this study is to investigate the influence of personality toward post purchase regret and. Furthermore, Big Five personality is examined in order to determine post purchase outcome regret and post purchase process regret. Finally, we detail and discuss the conclusions drawn from this study.

\section{Literature Review}

Regret is the emotion that has received the most attention from decision theorists (Michenaud, 2008). The experience of regret is more intense when the unfavourable outcomes are the result of action rather than of inaction, consumer experiences more regret over negative outcomes that stem from actions taken than from identical outcomes that result from actions foregone. Lee and Cotte (2009) explained that there were two dimensions of outcome regret, namely regret due to foregone alternatives and regret due to a change in significance. Regret due to foregone alternatives is that consumers compare their chosen alternative to the known foregone alternative and/or unknown foregone alternative.

Meanwhile, regret due to a change caused by consumer's perception of diminished product utility from the time of the purchase to a certain point in time after the purchase. Lee and Cotte (2009) also explained that that there were two dimensions of process regret. Regret due to under-Consideration (when individuals feel regret due to under-consideration, regardless of the purchase outcome, they are sceptical of the heuristic processing that led them to the purchase) and regret due to over-consideration (when individuals regret due to over-consideration, regardless of the outcome, they are regretting that they have put too much time and effort into the buying process) 
Connolly and Zeelenberg (2002) proposed two core components of regret as 1) the upwards, between-option counterfactual comparison, which they term "outcome regret" and 2) an intense feeling of responsibility and self-blame, which is based on the justifiability of the decision or decision process. In the context of consumer purchase decisions, the choice is often between selecting an option that appears safer given the available information (e.g., a well-known brand) and a riskier option (an unknown but cheaper brand).

When consumer perceives that their decision was unreasonable or inexplicable, they tend to feel responsible for making the poor decision. Decisions can become unpleasant when consumers feel they have made an incorrect choice. The intensity of regret in the context of consumption may increase depending on the characteristics of the situation and personality (Delacroix \& Jourdan, 2007). Thus, it proposes:

H1: personality positively related to post purchase regret

In literature of Big Five personality, neuroticism trait expressed as opposed to emotional stability. Neuroticism has special characteristics, which have irritability, low self-esteem, social anxiety, feelings of fear, it is easy to worry, anxiety and inconsistent (McCrae, Robert \& Costa, 2008). It also can affect the way consumers in the purchase of a product and regret after purchase the product (Zeelenberg \& Pieters, 2007). It has concluded that neuroticism is positively associated with post-purchase regret.

Consumer with neuroticism trait will be susceptible to regret. Meanwhile, openness to experience refers to how individuals are willing to make adjustments with an idea or a new situation (Iskandar \& Zulkarnain, 2013). Openness to experience have the feature is tolerant, high capacity to absorb information, focused, and able to be aware of the feelings and thoughts (McCrae, Robert \& Costa, 2008). Zeelenberg and Pieters (2007) proposed that consumers with less consideration or too much consideration in making a purchase could also experience post-purchase regret. Openness to experience associated with post-purchase regret because individuals with these traits tend to be a lot of consideration to the product to be bought. The scale of the NEO-PI-R reflects the tendency of their act of contrition because of the negative effects of which on the scale are in the phase of impulsiveness, which are not directly part of the trait openness to experience (Whiteside \& Lynam, 2001). It can be concluded that openness to experience tend to experience post-purchase regret.

In agreeableness trait, indicates that the individual has a good adaptation skills and lead to a friendly nature, the tendency to always give in, avoid conflict, and tends to follow others or conformity (McCrae, Robert \& Costa, 2008). Meanwhile, post-purchase remorse can occur when consumer do not think about or do not pay sufficient attention to the products to be purchased (Zeelenberg \& Pieters, 2007). Related to this, it could predict that individuals who have a dominant trait agreeableness will tend to perform conformity or follow others in making a purchase. So, when buying products, consumers may experience post-purchase regret to alternative products that not selected or regret for the sudden change of attitude. It concluded that agreeableness positively correlated with post-purchase regret.

Conscientiousness characterized by individual self-control of the social environment, think before act, delay gratification, follow the rules and norms, planned, organized, and conscientious (McCrae, Robert \& Costa, 2008). According to Joanna (2007), individuals who have dominant conscientiousness trait generally have high self-control in purchasing or seeking information about a product to purchase. Lee and Cotte (2009) explain that the post-purchase regret tends to be greater when consumer has excessive control to decisions than individuals who have little control over the decision. Thus, conscientiousness associated with post-purchase regret.

Individual with extraversion, characterized by attitudes such as having a high enthusiasm; love to hang out, have a positive emotional, energetic, interested in many things, ambitious, friendly towards others, have a high level of motivation, establish relationships with others, dominant in the environment, and can predict the development of social relationships (McCrae, Robert \& Costa, 2008). Post-purchase remorse is a cognitive emotion in which consumers deny, avoid, and arrange experiences that cannot happen again during the process of selecting and purchasing a product (Zeelenberg \& Pieters, 2007). Furthermore, Zeelenberg and Pieters (2007) also said that the regret may occur if consumers spend too much time and too much to consider looking for information about a product to be purchased. Regret 
may even manifest itself in situations when consumers are satisfied with their present selections. When comparing two alternatives and their respective outcomes, the satisfaction felt with a current selection is not necessarily important; instead, the determinant factor is whether the chosen alternative leads to a better or worse outcome than other available options (Bui, et al 2011).

$\mathrm{H}$ 2: There is a positive relationship between a) neuroticism, b) openness to experience, c) agreeableness, d) conscientiousness, e) extraversion with outcome regret.

H3: There is a positive relationship between a) neuroticism, b) openness to experience, c) agreeableness, d) conscientiousness, e) extraversion with process regret.

\section{Research Method}

In this study, two hundred and fifty-seven questionnaires distributed to undergraduate students at one of state university in Medan, Indonesia. Two hundred and seven questionnaires returned with complete answers. The response rate of this study was $81 \%$. The validity of the measurement tools measured by constructs validity that designed to measure whether certain factors can fulfil their functions.

Items in Post Purchase Regret Scale developed according to two-dimensions of purchase regret. Those dimensions are outcome regret and process regret (Lee \& Cotte, 2009). This scale used the Likert model with five answer choices. Factor analysis of post purchase regret scale showed that (1) Loading factor value for outcome regret ranges from 0.504 to 0.847 ; $(2)$ the loading factor value for process regret ranges from 0.530 to 0.808 ; The Alpha Cronbach coefficient of reliability of outcome regret $(\alpha=0.819)$ and process regret $(\alpha=0.824)$.

The Big Five Inventory scale is consisted neuroticism, openness to experience, agreeableness, conscientiousness, and extraversion (McCrae, Robert \& Costa, 2008). Respondent are requested to respond using five-point scaled response options. The factor analysis of Big Five Inventory showed that (1) Loading factor value for neuroticism ranges from 0.501 to 0.788 ; (2) The loading factor value for openness to experience ranges from 0.572 to 0.789 ; (3) The loading factors value for agreeableness ranges from 0.639 to 0.802 . (2) The loading factor value for conscientiousness ranges from 0.501 to 0.768 ; (3) Loading factors value for extraversion were 0.648 to 0.848 . The Alpha Cronbach coefficient of reliability of neuroticism $(\alpha=0.730)$, openness to experience $(\alpha=0.723)$, agreeableness $(\alpha=0.701)$, conscientiousness $(\alpha$ $=0.744)$, and extraversion $(\alpha=0.794)$.

\section{Result}

This study involved Two hundred and seven undergraduate students. Their ages ranged from 1721 years and the average were 19.38 years $(S D=1.29)$. Majority of participants, $54.1 \%$ was female. The result of Pearson correlation analysis showed that neuroticism, openness to experience, agreeableness, conscientiousness, and extraversion significantly correlated with post purchase regret, outcome regret and process regret. Result depicted in Table 1.

\begin{tabular}{|l|l|l|l|l|l|l|l|l|l|l|}
\hline Variables & Mean & SD & 1 & 2 & 3 & 4 & 5 & 6 & 7 & 8 \\
\hline 1. Post purchase regret & 28.70 & 4.65 & 1 & & & & & & & \\
\hline 2. Outcome regret & 14.75 & 2.54 & $0.819^{* *}$ & 1 & & & & & & \\
\hline 3. Process regret & 13.95 & 2.95 & $0.866^{* *}$ & $0.429^{* *}$ & 1 & & & & & \\
\hline 4. Neuroticism & 17.65 & 2.48 & $0.288^{* *}$ & $0.254^{* *}$ & $0.235^{* *}$ & 1 & & & & \\
\hline 5. Openness to experience & 17.07 & 2.85 & $0.236^{* *}$ & $0.211^{* *}$ & $0.190^{* *}$ & $0.531^{* *}$ & 1 & & & \\
\hline 6. Agreeableness & 17.97 & 2.52 & $0.265^{* *}$ & $0.251^{* *}$ & 0.202 & $0.447^{* *}$ & $0.579^{* *}$ & 1 & & \\
\hline 7. Conscientiousness & 21.65 & 3.28 & $0.255^{* *}$ & $0.240^{* *}$ & $0.194^{* *}$ & $0.414^{* *}$ & $0.484^{* *}$ & $0.615^{* *}$ & 1 & \\
\hline 8. Extraversion & 13.64 & 1.94 & $0.247^{* *}$ & $0.225^{* *}$ & $0.195^{* *}$ & $0.474^{* *}$ & $0.425^{* *}$ & $0.399^{* *}$ & $0.531^{* *}$ & 1 \\
\hline
\end{tabular}

$* * p<0.01$

Table 1. Correlation coefficients and significant levels among selected variables 
Table 2 Showed that results of stepwise multiple regression analysis summarized into two major steps. Step 1 showed that neuroticism positively and significantly correlated with post purchase regret (B neuroticism $=0.288 ; \mathrm{p}<0.01)$. The inclusion of this variable had explained 8.3 per cent of post purchase regret. In Step 2, neuroticism and Agreeableness significantly correlated with post purchase regret (B neuroticism $=0.212 ; ß$ agreeableness $=0.170 ; \mathrm{p}<0.01$ ).

\begin{tabular}{|l|l|l|c|c|c|c|}
\hline Variables & \multicolumn{1}{|c|}{$\mathrm{B}$} & $\mathrm{SE} \mathrm{B}$ & $\beta$ & \multicolumn{1}{c|}{$\mathrm{R}^{2}$} & $\Delta \mathrm{R}^{2}$ & $\mathrm{~F}$ \\
\hline $\begin{array}{l}\text { Post Purchase regret } \\
\text { Step 1 }\end{array}$ & & & & & & \\
$\begin{array}{l}\text { Constant } \\
\text { neuroticism }\end{array}$ & 19.176 & 2.230 & & 0.083 & 0.083 & $18.611^{* *}$ \\
\hline $\begin{array}{l}\text { Step 2 } \\
\text { Constant } \\
\text { neuroticism }\end{array}$ & 0.540 & 0.125 & $0.288^{* *}$ & & & \\
Agreeableness & 16.059 & 2.589 & & 0.106 & 0.098 & $5.293^{* *}$ \\
\hline$*{ }^{* *}<0.01$ & 0.397 & 0.138 & $0.212^{* *}$ & & & \\
\hline
\end{tabular}

Table 2. Results for stepwise regression analysis post purchase regret

Regarding to variable outcome regret, in step 1, it showed that neuroticism positively and significantly correlated with outcome regret $(\Omega$ neuroticism $=0.254 ; \mathrm{p}<0.01)$. In Step 2 , it found that neuroticism and Agreeableness significantly correlated with outcome regret $(B$ neuroticism $=0.178$; $ß$ agreeableness $=0.171 ; \mathrm{p}<0.01)$. This result confirms that neuroticism and Agreeableness contributed to outcome regret. Meanwhile, in variable process regret showed that neuroticism positively and significantly correlated with process regret $(\beta$ neuroticism $=0.235 ; \mathrm{p}<0.01)$. This result confirms that only neuroticism contributed to process regret. Result depicted in Table 3.

\begin{tabular}{|c|c|c|c|c|c|c|}
\hline Variables & B & SE B & $\beta$ & $R^{2}$ & $\Delta \mathrm{R}^{2}$ & $\mathrm{~F}$ \\
\hline $\begin{array}{l}\text { Outcome regret } \\
\text { Step } 1 \\
\text { Constant } \\
\text { neuroticism }\end{array}$ & $\begin{array}{l}10.159 \\
0.260 \\
\end{array}$ & $\begin{array}{l}1.232 \\
0.069 \\
\end{array}$ & $0.254^{* *}$ & 0.065 & 0.065 & $14.163^{\text {t* }}$ \\
\hline $\begin{array}{l}\text { Step } 2 \\
\text { Constant } \\
\text { neuroticism } \\
\text { Agreeableness }\end{array}$ & $\begin{array}{l}8.444 \\
0.182 \\
0.172\end{array}$ & $\begin{array}{l}1.431 \\
0.076 \\
0.075\end{array}$ & $\begin{array}{l}0.178^{* *} \\
0.171^{* *}\end{array}$ & 0.088 & 0.023 & $5.249^{* *}$ \\
\hline $\begin{array}{l}\text { Process regret } \\
\text { Constant } \\
\text { Neuroticism }\end{array}$ & $\begin{array}{l}9.017 \\
0.280\end{array}$ & $\begin{array}{l}1.437 \\
0.081\end{array}$ & $0.235^{* *}$ & 0.055 & 0.055 & $12.028^{\text {t* }}$ \\
\hline
\end{tabular}

Table 3. Results for stepwise regression analysis of outcome and process regret

\section{Discussion}

The results showed that all dimensions of the Big Five Personality correlated with post-purchase regret. It demonstrated that Big Five Personality is an important construct of study when explaining consumers post purchase regret. According to Creyer and Ross (1999), regret caused by a lack of effort in seeking information about a product to be purchased and the presence of previous or antecedent factors. Remorse after buying emerges due to personality factors from within the individual. Creyer and Ross (1999) suggested that personality characteristics can lead to a predisposition in decision-making is based on the wealth of experience of regret purchase (McElroy \& Dowd, 2007). On the dimension of the Big Five Personality explained that within the individual personality consists of five dimensions. Fifth dimension is used to describe differences in cognitive behavioural, affective, and social.

This study found that a positive correlation between the dimensions of openness to experience with post-purchase regret. Openness to experience refers to how individuals are willing to make 
adjustments on an idea or a new situation. Openness to experience having easy tolerance characteristics has the capacity to absorb information, and acting impulsively (McCrae, Robert \& Costa, 2008). Customer with openness to experience (have the capacity to absorb information and act impulsively) would be very likely to suffer remorse for not paying attention or are looking for more information on the products to be purchased for individuals to buy products that are not planned. Consumer will reduce cognitive evaluation in buying a product and act notice the consequences that will come after bought the product. At the time of purchasing a product, individual with openness to experience not consider things before deciding on when to buy and Regret for their alternative was not selected or do not know enough information about the product to be purchased (Zeelenberg \& Pieters, 2007).

The results showed that a relationship between conscientiousness with post-purchase regret. Conscientiousness dimension described thinking before acting, delayed gratification, follow the rules and norms, have the self-control of the social environment, and conscientious (McCrae, Robert \& Costa, 2008). Ali and Asrori (2008) suggested individuals who have high self-control in the purchase of a product would get as much information about the product. Instead of self-control is low in purchasing a product will cause less people searching for information about the product to buy. Conscientiousness trait described as individuals who have self-control against the environment (Zulkarnain et al., 2015). Post purchase regret is impact of low self-control against a purchase. Individuals with low self-control less attention to the proper ways to behave in a situation that is varied and less able to change their behaviour in accordance with the demand of social situations. Low self-control of the purchase may result in an adverse impact.

Another founding showed that a relationship between extraversion trait with post purchase regret. Extraversion trait characterized by a positive attitude as having a high enthusiasm, like to hang out, have a positive emotional, energetic, interested in many things, ambitious, friendly towards others, have a high level of motivation in the mix, establish relationships with others, and dominant in its environment and can predict the development of social relationships (McCrae, Robert \& Costa, 2008). It can be concluded that individuals with extraversion to be more searching for information about the product to be purchased. Creyer and Ross (1999) states that the factors affecting regret is individual involved in the purchasing process.

The results showed a relationship between agreeableness trait with post-purchase regret. Agreeableness trait was described as friendly people, tend to have a personality that always give in, avoid conflicts and to follow others or conformity (McCrae, Robert \& Costa, 2008). Post-purchase regret can occur when consumer do not think about or do not pay sufficient attention to the products to be bought. In other words, post-purchase regret arising from lack of consideration for the product to purchased so that the individual can expose to negative consequences or regret later (Zeelenberg \& Pieters, 2007). The tendency to follow others or conformity at the time of buying the product can cause the individual concerned did not pay attention to the need for the product, do not notice the quality, and did not find out about the products to be purchased so that these individuals may experience regret after buying. Individuals with dimension of agreeableness may experience regret for the lack of consideration when buying a product because of the encouragement of those who ultimately will affect the behaviour to switch to another option.

This study also showed that a relationship between neuroticism with post-purchase regret. According to McCrae, Robert and Costa (2008), neuroticism trait can be classified into personality that has irritability, low self-esteem, social anxiety, feelings of fear, it is very easy to worry, anxiety and inconsistent. In some of, neuroticism is the opposite of emotional stability (McCrae, Robert \& Costa, 2008). Zeelenberg and Pieters (2007) states that the regret may occur caused of the lack of consideration of a product and inconsistent behaviour when purchasing the product. Inconsistent behaviour is the nature of the individual with neuroticism trait.

McElroy and Dowd (2007) states that regret is inconsistency of consumer behaviour during the selection process of purchasing the product. Lin (2006) also found that individuals who are in a negative emotional state would be more likely to take risks in decision-making processes than individuals who are in a positive emotional state. The more negative emotions felt by the consumer, the worse the purchasing decisions they make, so that consumers are likely to experience post-purchase regret. 
The result of stepwise regression analysis, we found that neuroticism and agreeableness influenced to post purchase regret and outcome regret. Meanwhile, only neuroticism influenced to process regret. It obviously that neuroticism is predictor of regret even outcome or process. Individuals with neuroticism, tend to experience unpleasant and disturbing emotions and emotional instability more likely to experience stress in daily life than those who have low level of neuroticism. Regret is associated with feelings of self-blame, a drive to correct one's mistake, and a tendency to ruminate and focus on past events. It is an unpleasant feeling, coupled with a clear sense of self-blame concerning its causes and strong wishes to undo the current situation. Roese et al., (2007) investigated about negative emotions such as anger, anxiety, boredom, fear, guilt, and sadness and found that regret rated as being the most intense of these negative emotions. It could conclude that neuroticism is associated with regret.

\section{Conclusion}

The study has a number of limitations, participants answered a survey and data based on selfreported answers. Results may affect by social desirability and recall bias. The generalizability may apply to those who decided to participate in the study. The study examined the impact of personality on consumer regret. The big five personality variables, neuroticism had the strongest influence on outcome regret and process regret, while openness to experience had the least influence. Therefore, future studies can investigate other variables that might be associated with both post-purchase regret (outcome and process) and their relationship antecedents. After the consumer has purchased the product, the consumer will evaluate the satisfaction level. If the consumer feels regret, expectations towards the product have not been met. In order to experience regret, individuals must also be able to construct alternative scenarios other than the current state. Anticipated regret proved to lead to increased levels of effort, when consumer executes his/her behavioural intentions. This suggests that behavioural intentions are more likely to motivate and energize the target behaviour when they embodied with anticipated regret. Present study could be regarded trying to concentrate on the role of personality in anticipated-regret in consumers' decisions, and implicitly depicting the possible useful effects of it, for the consumer. An ability to externally shift responsibility for bad choices can reduce aversive feelings of regret. Consumers are regret adverse; therefore, their choices are made based on what they believe will result in minimal amounts of future regret. To prevent future regret, consumer may try to improve the quality of the decision process and outcomes, for instance, by increased internal (memory) or external information search.

\section{References}

Ali, M. \& Asrori, M. (2008). Adolescent psychology: Development of learners. Jakarta: Bumi Aksara.

Bui, M.Y, Krishen, A.S., \& Bates, K. (2011). Modeling regret effects on consumer post-purchase decisions. European Journal of Marketing, Vol. 45 (7/8), pp.1068-1090.

Creyer, H.E. \& Ross, W.T. (1999). The development and use of a regret experience measure to examine the effects of outcome feedback on regret and subsequent choice. Marketing Letters, 10(4), pp. 373-386.

Delacroix, E., \& Jourdan, P. (2007). Consumer tendency to regret: Validation of a measurement scale scale. Recherche et Applications en Marketing (English edition), 22(1), pp. 25-44.

Hawkins, D.I, Mothersbaugh, D.L. \& Best, R.J. (2007). Consumer behaviour building marketing strategy. New York: Mc Graw Hill.

Iskandar, L.M., \& Zulkarnain. (2013). Penyesalan pasca pembelian ditinjau dari big five personality [Post purchase regret based on personality]. Jurnal Psikologi, 40(1), pp.51-61

Joanna, C. (2007). Online information search and purchase: The influence of demographics and psychographics. Thesis. Hong Kong University.

Lee, S.H. \& Cotte, J. (2009). Post-purchase consumer regret: Conceptualization and development of the PPCR scale. Advances in Consumer Research, 36, pp. 456- 462.

Lin, C.H. (2006). The influence of unawareness set and order effects in consumer regret. Journal of Business and Psychology, 21(2), pp. 293-311.

M'Barek, M. and Gharbi, A. (2012). Management of Post-Purchase Regret. Journal of Supply Chain and Customer Relationship Management, pp. 1-9

McCrae, Robert R., \& Costa, P.T. (2008). The five-factor theory of personality. In Handbook of personality: Theory and research. 3d ed. Edited by Oliver P. John, Richard W. Robins, and Lawrence A. Pervin, 159-181. New York: Guilford

Michenaud, S. (2008). Applying regret theory to investment choices: Currency hedging decisions, Journal of International Money and Finance, 27, pp. 677-694

www.jbrmr.com A Journal of the Academy of Business and Retail Management (ABRM) 
Pieters, R. \& Zeelenberg, M. (2007). A theory of regret regulation 1.1. Journal of Consumer Psychology, 17(1), pp. 29-35.

Roese, N. J., Summerville, A. \& Fessel, F. (2007). Regret and behavior: Comment on Zeelenberg and Pieters. Journal of Consumer Psychology, 17, pp. 25-28.

McElroy, T. \& Dowd, K. (2007). Action orientation, consistency and feelings of regret. Judgment and Decision Making, 2(6), pp. 333-341.

Whiteside, S.P. \& Lynam, D.R. (2001). The five factor model and impulsivity: Using a structural model of personality to understand impulsivity. Personality and Individual Differences, 30, pp. 669-689.

Zeelenberg, M. and Pieters, R. (2007). A Theory of Regret Regulation 1.1, Journal of Consumer Psychology, 17(1), pp. 318.

Zulkarnain, Pohan, V.G.R. \& Sulistyawati, E. (2015). Kecemasan dalam menghadapi assessment centre di kalangan pekerja telekomunikasi [Assessment centre anxiety among telecommunication employee]. Jurnal Psikologi, 42(3), pp. 259-277 